\title{
CR Research Square \\ Predictive Role of Psychosocial Factors in Older Adults Life Satisfaction
}

Shahab Papi

Department of Health Education \& Promotion, Faculty of Health, Tabriz University of Medical Sciences, Tabriz,

Maria Cheraghi ( $\nabla$ mariacheraghi@gmail.com )

Ahvaz Jundishapur University of Medical Sciences https://orcid.org/0000-0002-6628-8786

Research article

Keywords: Life satisfaction, older adults, psychological, Social factors.

Posted Date: August 17th, 2019

DOI: https://doi.org/10.21203/rs.2.13091/v1

License: (c) (1) This work is licensed under a Creative Commons Attribution 4.0 International License.

Read Full License 


\section{Abstract}

Background: The older adults are a part of society whose population is increasing as science progresses and health conditions improve. Social, psychological and behavioral factors will be influenced on life satisfaction in older adults. We aimed to predictive role of psychosocial factors in life satisfaction older adults. Methods: It was a descriptive-analytical study which has conducted on 679 older adults through convenience sampling from Qom city during 2018. The data were collected using demographic characteristics, life satisfaction, well-being, cognitive status, social support, and daily activities of life. Data were analyzed by SPSS software version 22 and independent t-test, ANOVA, Pearson's correlation coefficient and multiple regression analysis. Results: The mean and standard deviation of older adults age was $70.43 \pm 7.62$ years. The mean life satisfaction score was $13.77 \pm 3.73$. The results showed a significant relationship between job and education with life satisfaction $(P<0.001)$. The results also showed that social support $(P=0.001)$ and daily activities $(P=0.017)$ significantly predict the level of life satisfaction, and the dimensions of health $(P=0.001)$ and cognitive status $(P=0.007)$ have a larger share in predicting the satisfaction of older adults life. Conclusion: We found that some parts of life changes in older adults can be predicted with the help of social support, health status, cognitive status, and everyday life activities. Therefore, in order to increase the level of satisfaction of older adults life, it is suggested that the field of promotion of social support, health status, and cognitive status be provided.

\section{Background}

The older adults are a group of people who, in the contemporary world, has a growing population with special needs by huge advances in science and technology, especially the promotion of health sciences, and governments are required to pay more attention to this group (1).According to the World Health Organization (WHO), currently around 650 million people are over 60 years old and by 2050 this figure is expected to reach two billion. Today, $60 \%$ of the world's older adults live in developing countries, which will reach $80 \%$ by 2050 . The older adults population in Iran is increasing, and its population is expected to increase from $8.2 \%$ in 2011 to $10 \%$ in $2021(2,3)$.

Life satisfaction has recently been introduced as the best indicator of the quality of life (4). Satisfaction with life is a kind of general and deep inner happiness that emanates from individual experiences in the outside world. In other words, it expresses the positive attitude of the individual towards his life and reflects the individual's feelings about his past, present or future $(5,6)$. Older adults have a higher life satisfaction also appear to be at higher levels in promoting health behaviors (7). However, it is usually difficult to achieve higher levels of life satisfaction by increasing age and physical and psychological problems (8). Meanwhile, lifestyle of older adults plays an important role in their satisfaction. It seems that economic, social and cultural factors affect life satisfaction of older adults (9). Many of the satisfactory predictor factors of older adults are social, psychological, and behavioral, and potentially changeable. Success in older adults is not affected by individual genetic factors, but more factors such as the level of physical activity, social interaction and social support will be effective on older adults satisfaction (10). The results a study by Li et al. showed that life satisfaction in older adults is associated 
with the level of education, financial resources, self-assessment of health, receiving financial support from the children and satisfying their support, staying at home, seeing and visiting neighbors, and inviting them to dinner (11). Didino et al., reported that factors such as income, level of home equipment and anxiety and loneliness are effective on life satisfaction of older adults (12). Bishop et al. described individual access to key and important life sources as factors influencing life satisfaction. These resources include material, social or personal resources that the older adults have to offer, which can be referred to as the main sources for advancing and maintaining the well-being of individuals. These resources can also help the older adults achieve their personal goals and meet the basic physical and psychological needs (13).

Based on the above and given significant impact of social, psychological and behavioral factors on life satisfaction, in this study, we intended to predictive role of psychosocial factors in life satisfaction older adults.

\section{Methods}

It was a descriptive-analytical study in 2018. The research population consisted of all older adults living in Qom city. G*Power-3 software was used to calculate the sample size (14). Considering the $95 \%$ confidence level, $80 \%$ test power, and $r=0.30,544$ were calculated according to the study of Ataollahi et al. (15).To compensate for sample loss and incomplete questionnaires, $20 \%$ of the sample size was added to the final samples and the final sample size was calculated 679 . The calculated sample size is in accordance with the number of samples proposed for Dyadic analysis (16).

Inclusion criteria for the study included speaking ability, satisfaction to participate in the study, age over 60 , lack of cognitive problems such as Alzheimer's. Older adults' medical records were used to judge these problems as well as older adults patients' records. Exclusion criteria were dissatisfaction with continued cooperation. Data collection was done in one step using a questionnaire consisting of 6 sections by researchers in public places where the target group was referred. The questionnaires were filled out by well-educated older adults under the supervision of questioners and for low-educated or illiterate elders, questionnaires were completed through an organized interview.

\section{Research Tools}

Demographic information questionnaire: The questionnaire included age, gender, employment status, marital status, educational level, income source, number of children and housing status.

Life Satisfaction Index-Z (LSI-Z): This questionnaire has 13 questions, designed in 1969 by Wylie, Wood, and Sheafor. Each of the questions is answered in the form of "I do not know", "agree" and "disagree", and the 2-1-0 system is used the scoring the answers.

In this way, "I do not know" is scored zero; in positive questions, "agree" is scored 2 and "disagree" is score 1 and in the case of negative questions, "disagree" is scored 2 and "agree" is score 1 . The total 
score of life satisfaction is estimated0-26. Obviously, a higher score indicates a higher level of life satisfaction. Regarding the interpretation of the LSI-Z score, $\leq 12$ indicate a low level of satisfaction, 1321 average satisfaction, and $22 \leq$ high satisfaction (17.18).

In Iran, the validity and reliability of this questionnaire are verified in different studies. Taghribi et al. reported the reliability coefficient of the tool through re-test with ICC coefficient as 0.93 . Cronbach's alpha coefficient of the present questionnaire was estimated 0.79 (19).

Activities of Daily Living (ADLs): In the present study, the 6-itemversion of Katz was used. This tool includes personal grooming items, eating, dressing, sitting, bathing, and controlling urine and feces. Each item has three options: "dependent" (zero points), "need help" (1 point) and "independent" (2 points).

The overall ADL score is from zero to 12 and each test is ranked "dependent" (0 to 4 points), "need help" (5 to 8 points) and "independent" ( 9 to 12 points) based on the score it earns. The validity and reliability of this tool have been proven by Katz (20).

WHO (Five) Well-Being Index (1998 version): This scale consists of five questions that assess the mental status of individuals over the past two weeks in a table. These five questions with the Likert technique include 6 options of "at all times" (score 5), "most often" (score 4), "slightly more than half of the times" (score 3), "slightly less than half of the times" (score 2), "sometimes" (score 1) and never (0 score).To compute the points, the numbers in the squares are summed up and multiplied by 4 . The resulting number ranges from zero to 100 , which points to a greater degree of well-being.

Medical Outcomes Survey (MOS): This scale was created in 1991 by Sherborne and Stewart and provides social support received by the subject. The questionnaire, which is a self-report tool, has 19 sentences, and the subject specifies the amount of disagreement or agreement with each of the expressions bya 5point Likert scale ( 1 point for "never" to 5 points for "always"). The lowest score in this test is 19 and the highest score is 95 . To get the overall score, all scores are combined.

The high score of the subject on this scale indicates that the subject has favorable social support. To obtain the score for each sub-scale, it is enough to merge the scores for the phrases associated with each sub-scale. The validity and reliability of this scale have been reported desirable. The reliability of this test has been reported using Cronbach's alpha coefficient in the range of 0.74-0.93 (21).

Abbreviated Mental Test (AMT): This questionnaire contains 10 simple and short questions that measure orientation, focus/attention, short-term memory, and long-term memory, and is used to screen for cognitive impairment including dementia and delirium in the elderly. The short form consists of 10 questions with 10 points, which takes only 3 minutes to complete.

This test has been validated in Iran and its scoring is so that the score below 6 is suspected of moderate cognitive disorder, a score of 6 to 8 is suspected of mild disorder, and a score higher than 8 means a lack of cognitive disorder. The intrinsic reliability of the Persian version of AMT is acceptable (Cronbach's 
alpha coefficient is 0.76 ), and its external reliability is also desirable (inter-group correlation coefficient is 0.89) (22).

In order to observe ethical considerations in this study, the samples participated in the research project while informing about the goals of the study. Information was also collected without the need to insert personal and in an organized manner.

\section{Data analysis}

In this study, data analysis was done using SPSS software version 22 at two descriptive and inferential levels. Descriptive statistics of mean and standard deviation and frequency distribution were used at the descriptive level. Independent T-test, ANOVA, Pearson's correlation coefficient and multiple regression analysis were used at the inferential level. The significance level of these tests was considered less than 0.05 .

\section{Results}

The mean age of the older adults was $70.43 \pm 7.62$ years in the range of 60 to 92 years. Also, $68.9 \%$ (468 cases) were female and $31.1 \%$ (211 people) were male. $51.8 \%$ (352) married, $46.5 \%$ (316) lost their spouses and only $1.1 \%(11)$ was divorced.

The majority of participants, $91.8 \%$ (623), were illiterate and or low-educated. Also, the mean of life satisfaction score in the case group was $13.77 \pm 3.73$ (range $3-26$ ), of which $41.8 \%$ (284 people) had low life satisfaction, $54.2 \%$ (368 people) had medium life satisfaction and $4 \%$ ( 27 people) had high life satisfaction.

According to independent t-test, life satisfaction was significantly correlated with the employment status and education of the older adults $(P<0.001)$, so that the mean of life satisfaction score in the older adults who were employed and had university education was significantly higher. ANOVA test results showed no significant difference in mean of life satisfaction score in terms of the number of children $(P=0.059)$ and housing status $(P=0.493)$ (Table 1$)$.

There was a positive and significant correlation between life satisfaction scores with health status, cognitive status and social support $(P<0.001, r=0.333, P<0.001, r=0.186, P<0.001, r=0.291)$. However, there was no relationship between life satisfaction with age and daily activities of subjects $(P=0.614, r=$ $-0.019, P=0.564, r=0.022$ ) (Table 2).

Stepwise linear regression analysis was used to investigate the effect of each of the predictors affecting life satisfaction in the older adults. According to the results, there was a positive and significant relationship between health $(\beta=0.253)$, social support $(\beta=0.204)$ and cognitive status $(\beta=0.17)$ with life satisfaction, and the relationship between daily activities of life and life satisfaction was negative and significant $(\beta=-0.91)$. 
According to the determination coefficient, about $16.3 \%$ of the changes in satisfaction with older adults life were due to the four variables mentioned in the regression model. The regression model had acceptable fitness $(P=0.001, F=23.21)$ (Table 3$)$.

\section{Discussion}

The purpose of this study was to determine the predictive role of psychosocial factors in satisfaction of older adults life. The results of this study showed that the majority of the older adults studied had low and moderate life satisfaction, which, in general, did not show favorable conditions. A glance at past studies suggests that the satisfaction of older adults life is not favorable $(11,23)$. However, in some studies, the satisfaction of the older adults with his current life is desirable $(12,15)$. Perhaps this is because the standard LSI-Z questionnaire was used in this study, but in other studies, a researcher-made checklist was used. Also, cultural differences can be the reason for differences in the state of satisfaction with the lives of individuals. In terms of demographic variables, life satisfaction was higher in men than in women. In the study of Hosseini et al., there was a significant difference between older adults men and women in terms of life satisfaction (24). However, the results of the study by Ataollahi Ashkevar et al. (15) contradicted this finding.In the present study, married older adults reported a higher living satisfaction than divorced ones or older adults people who lost their spouse. In a study by Botha and Booysen (25), married people had a higher life satisfaction than non-spouses. Cha's study also found more satisfaction with married life (26).

In addition, in the present study, life satisfaction was associated with the employment status of the older adults, so that older adults who were employed had higher satisfaction than other occupational groups. This finding was consistent with some studies (26-27). However, it was contradictory to the results of the study by Ataollaho Ashkevar et al. (15). In this study, life satisfaction was associated with the educational level of the subjects,so that life satisfaction in people with academic education was significantly higher than that in other groups. The findings of some studies $(11,26)$ were consistent with the present study. However, the results of the study by AtaollahiAshkevar et al. (15) contradicted this finding. Perhaps the reason for the inconsistency is the use of the standard LSI-Z questionnaire in this study and the use of a researcher-made checklist in other studies.

In the present study, there was a significant relationship between life satisfaction and the source of income, so that the mean score of life satisfaction in people who had the ability to buy and save was higher than that in other people. Didino et al. (12) also reported that higher income levels for older adults were associated with higher living standards. In study Lim et al. (29), life satisfaction was also associated with the economic situation of the older adults. The results of the study by Ataollah Eshkevar et al. (15) contradicted the findings of the present study. Cultural differences can be the cause of the difference in the state of satisfaction with the lives of individuals. In this study, life satisfaction was higher in the elderly with fewer children, but this difference was not significant. Also, there was no relationship between life satisfaction and housing status in the present study. Findings of the research by Ataollahi Ashkevar et al. (15) were consistent with the present study. However, in studying Lim and 
colleagues, life satisfaction was associated with housing status (28). In study Li et al., Life satisfaction was associated with staying at children's homes. In Karimi et al. (30), the mean score of life satisfaction in the older adults group living in the home was significantly higher than that in other groups.

In the present study, there was no relationship between life satisfaction with age. The study of Ataollahi Ashkevar et al. (15) also reported the lack of effect of the age factor on life satisfaction. However, Angelini et al. (31) stated that with increasing age, the level of life satisfaction increased.

In the present study, a direct and significant correlation was found between life satisfaction with health status. The results of some studies $(32,33)$ were consistent with these finding.The results of this study showed a direct correlation between life satisfaction and cognitive status. In the study of Ataollahi Ashkevar et al. (15), unlike the present study, there was no relationship between cognitive status and life satisfaction.

With the destruction of cognitive functions over time, older adults people are increasingly reluctant to perform routine personal activities and become more dependent on others, and in advanced stages of the disorder, they need to be admitted to hospitals and clinics. These conditions reduce self-esteem, anxiety, and depression in them, which affects the quality of life in terms of life satisfaction (34). According to the results of this study, a direct and significant correlation was found between social life satisfaction and social support. Li et al. (11) confirmed this finding in their study. Seeman and Adler (10) considered interactions and social support effective on the satisfaction of older adults. Young said in research that family support has increased life satisfaction in the older adults (35). In Iran, Babapour et al. (36) also reported a significant relationship between social support and life satisfaction in the elderly. Given that Iran's society is aging and older people are being transferred to institutions more than ever, it can be anticipated that more elderly people will be at risk of falling social support, and maybe their living satisfaction may be reduced. In this research, there was also no relation between daily activities of life and life satisfaction. However, in the study of Good et al., unlike the present study, there was a significant relationship between life satisfaction with daily activities of life and the state of independence (37).In the present study, health, social support, daily activities of life and cognitive status were identified as lifesatisfaction predictors, so that health, social support and cognitive status had a positive relationship with life satisfaction, but there was a significant negative relationship between life satisfaction with the daily activities of life of the people under study. Perhaps the reason for this is the cultural differences in Iranian societies with other societies. In Iranian societies, being dependent on everyday activities as well as social support by others, especially children, increases life satisfaction. Based on the results, it can be argued that by focusing on some of the psychological and social factors mentioned above, the elderly's satisfaction with their lives can be affected. Therefore, it is recommended to plan families in order to determine the causes of life satisfaction reduction with regard to its predictors.

This study had limitations, the most important of which was the low literacy level of the majority of older adults under study, the length of questions in the questionnaire, and the elderly's boredom in responding to them, which prolonged the process of work and reduced the quality of the answers, and there is a 
widespread negative attitude that many research on the older adults is not aimed at helping them, and only by researchers to advance their own goals. Another limitation of the present study was the crosssectional nature of the study which made it difficult to determine the causal relationship. Therefore, it is advisable to use more lengthy and more comprehensive studies of the factors affecting life satisfaction and the causal relationship. On the other hand, doing this study in a case-control study could provide valuable information to the research team.

\section{Conclusions}

Our findings showed that life satisfaction in the older adults was not desirable. Therefore, the necessity of using solutions to improve life satisfaction in older adults community that is weaker in this category is felt. Social support, health and cognitive status and daily activities of life as well as life satisfaction determinants were reported. Considering that the mentioned factors explained $16.3 \%$ of life satisfaction, other studies to identify other factors affecting life satisfaction are needed.

\section{Declarations}

- Ethics approval and consent participate: Our study was approved by independent Ethics Committee of Ahvaz Jundishapur University of Medical Sciences by Ethics Number: IR.AJUMS.REC.1397.898.

Verbal Consent was obtained from the study participates in this research, and was approved by the independent Ethics Committee of Ahvaz Jundishapur University of Medical Sciences.

- Consent for publication: Not applicable

- Availability of data and material: Not applicable

- Competing interests: There are no competing interests for authors.

- Funding: Not applicable

- Authors' contributions: Shahab papi, conceived and designed analysis, collect the data, performed the analysis. Dr. Maria Cheraghi conceived and designed analysis, wrote the paper and mange the project.

All authors have read and approved the manuscript, and were agree to be accountable for all aspects of the work.

- Acknowledgments: This study was part of a research project under the code of ethics IR.AJUMS.REC.1397.898 and supported by the deputy of research in Ahvaz Jundishapur University of Medical Sciences, Ahvaz, Iran. Authors would like to express their gratitude and appreciation to the patience, and cooperation of all older adults participated in this study.

- Disclosure

The authors report no conflicts of interest for this work. 


\section{References}

1. KarimiTorghabeh E, Ehsani M, Koozechian H, Mehrabi Y. Effect of 16 weeks walking with different dosages on psychosocial function related quality of life among 60 to 75 years old men. Iranian Journal of Ageing. 2011; 5(18):21-29.

2. Moshfeghi G, Rezabaakhsh H, Danesh A. Effectiveness of horticulture therapy on depression among older adults in nursing homes. Advances in Nursing \& Midwifery. 2014;24(86):17-26.

3. Statistical Center of Iran. Implementation of the 2011 Iranian Population and Housing Census; 2011. Available from: http:// www.who.int/kobe_centre/ageing/en/-2011.

4. Fernandez_Ballesteros R, Zamarrón MD, Ruiz MÁ. The contribution of socio-demographic and psychosocial factors to life satisfaction. Ageing and Society. 2001; 21(1):25-43.

5. Rabani R, Behesgti SS. Experimental Investigation ofthe relationship betweenreligiosityand life satisfaction. Journal of Social Sciences (Faculty of Human Sciences, Ferdowsi University of Mashhad). 2011; 79-102.

6. Matteson M A, Mcconnell E, Linton A, Gerontological nursing, Philadelphia, Saunders; 1997.

7. Ozer M, A Study on the Life Satisfaction of Elderly Individuals Living In Family Environment and Nursing Homes, Turkish Journal of Geriatrics 2004; 7(1):33-36.

8. Kubilay G. An Overview to Sentence, Program of Training Project for Helping Elderly at Home 1994:15.

9. Gholizadeh A, Shirani E. Relationships among individual, familial, social, economic and life satisfaction of the elderly of Isfahan, Applied Sociology 2010; 21(37):69-82.

10. Seeman TE, Adler N. Older Americans: Who will they be? National Forum. 1998; 78(2):22-26.

11. Li H, Chi I, Xu L. Life satisfaction of older Chinese adults living in rural communities. Journal of cross-cultural gerontology. 2013;28(2):153-1

12. Didino D, Frolova EA, Taran EA, Gorodetski K. Predictors of Life Satisfaction among Older Adults in Siberia. The European Proceedings of Social \& Behavioural Sciences (EpSBS) Vol 7: Lifelong Wellbeing in the World (WELLSO 2015)-Nicosia, 2016. 2016;72015:400-7.

13. Bi shop AJ, Martin P. Happiness and congruencein older adalhood. A Structural model of life satisfaction. Aging and mental Health. 2006,10,445-453.

14. Faul F, Erdfelder E, Lang AG, Buchner A. G* Power 3: A flexible statistical power analysis program for the social, behavioral, and biomedical sciences. Behavior research methods. 2007 May 1;39(2):17591.

15. AtaollahiEshkoorS, TengkuAizan H, Yoke MunCh, Shahar S. An Investigation on Predictors of Life Satisfaction among the elderly. International Journal of Advances in Social Sciences. 2015; 1(2):207212.

16. Fuchs P, Nussbeck FW, Meuwly N, Bodenmann G. Analyzing Dyadic Sequence Data-Research Questions and Implied Statistical Models. Frontiers in psychology. 2017 Apr 11;8:429. 
17. Wood V, Wylie ML, Sheafor B. An analysis of a short self-report measure of life satisfaction: correlation with rate judgment. Journal of Gerontology 1969; 24: 465-69.

18. Lawton MP. The functional assessment of elderly people. Journal of the American Geriatrics Society 1971; 19: 465-81.

19. Tagharrobi Z, Tagharrobi L, SharifiKh, Sooki Z. Psychometric evaluation of the Life Satisfaction Index-Z (LSI-Z) in an Iranian elderly sample. Payesh. 2011; 10(1):5-13.

20. Katz S, Ford AB, Moskowitz RW, Jackson BA, Jaffe MW. Studies of illness in the aged: the index of ADL: a standardized measure ofbiological and psychosocial function. JAMA 1963; 185(12): 914-19.

21. SherbourneCD,StewartAL. The MOS social support survey. Social Science Medicine, 1991; 32: 71314.

22. Bakhtiyari F, Foroughan M, Fakhrzadeh H, Nazari N, Najafi B, Alizadeh M, et al. Validation of the persian version of Abbreviated Mental Test (AMT) in elderly residents of Kahrizak charity foundation. Iranian Journal of Diabetes and Metabolism. 2014;13(6):487-94.

23. Borhaninejad VR, Nabvi SH, Lotfalinezhad E, Amini F, Mansouri T. Relationship between Social participation and life satisfaction among older people. Journal of North Khorasan University of Medical Sciences. 2017 Mar 15;8(4):701-11.

24. Hosseini SM, Rezaee AM, Keykhosravi Z. A Comparison of old men and women's social support, life satisfaction, happiness and depression. Journal of woman and society. 2012; 4(8):143-161.

25. Botha F, Booysen F. The relationship between marital status and life satisfaction among South African adults. Acta Academia. 2013; 45(2):150-178.

26. Cha YJ. Correlation between Leisure activity time and life satisfaction: Based on KOSTAT time use survey data. Occupational Therapy International. 2018; 2018(5154819):1-9.

27. Alden L, Hammarstedt M. Self-emplioyment and life satisfaction among the elderly. Survey-based evidence from Sweden. Linnaeus University Discrimination and Integration. 2017;5:1-32.

28. Jahangirzadeh $P$, KhodabakhshiKoolaee $A$. The relationship between self-concept, life satisfaction and hope among retired and housewife older adults' women. Journal of Gerontology. 2016;1(1):1928.

29. Lim HJ, Min DK, Thorpe L, Lee CH. Multidimentional construct of life satisfaction in older adults in Korea: a six-year follow up study. BMC Geriatrics. 2016;16:197.DOI:10.1186/s12877-016-0369-0

30. Karimi T, Nouhi E, Iranmanesh S. Comparing Life satisfaction of elderly between nursing home residents and seniors living in their own homes in Isfahan. Journal of Geriatric Nursing. 2014;1(1):4354.

31. Angelini V, Cavapozzi D, Corazzini L, Paccagnella O. Age, Health and Life Satisfaction among older Europeans. Social Indicators Research.2012;105(2):293-308. DOI:10.1007/s11205-011-9882-x

32. Gongora VC, Castro Solano A. Well-being and life satisfaction in Argentinean adolescents. Journal of Youth Studies. 2014 Oct 21;17(9):1277-91. DOI: 10.1080/13676261.2014.918251. 
33. Jafari E, Heshmati R. Life satisfaction, spirituality well-being and hope in cancer patients. ProcediaSocial and Behavioral Sciences. 2010; 5: 1362-1366. https://doi.org/10.1016/j.sbspro.2010.07.288.

34. Clare L, Woods RT. Cognitive training and cognitive rehabilitation for people with early-stage Alzheimer's disease: A review. Neuropsychological rehabilitation. 2004 Sep 1;14(4):385-401.

35. Family relations and life satisfaction of older people: a comperative study between two different hukous in China. 2012;32(1):19-40. DOI:10.1017/S0144686X11000067

36. BabapourM, Raheb Gh, Eghlima M. The Relationship between Social Support and Life Satisfaction among Elderly Nursing Home Residents in Tehran. Salmand. 2014; 9(1):6-12.

37. Good GA, La Grow SJ, Alpass FM. A Study of Older Adults: Observation of Ranges of Life Satisfaction and Functioning. New Zealand Journal of Psychology. 2011; 40(3):96-103.

\section{Tables}

Table 1. Comparison of life satisfaction at different levels of the variables studied 


\begin{tabular}{|c|c|c|c|c|}
\hline \multirow[t]{2}{*}{ Variable } & \multirow[t]{2}{*}{ Variable levels } & \multirow[t]{2}{*}{ Number (\%) } & Life satisfaction & \multirow[t]{2}{*}{ P-Value } \\
\hline & & & Mean \pm SD & \\
\hline \multirow[t]{6}{*}{ Employment status } & Current worker & $18(2.7)$ & $17.61 \pm 2.97$ & \multirow[t]{6}{*}{$<0.001$} \\
\hline & Employed after retirement & $16(2.4)$ & $13.75 \pm 3.19$ & \\
\hline & Retired & $175(25.8)$ & $14.38 \pm 3.70$ & \\
\hline & Unemployed & $49(7.2)$ & $13.67 \pm 3.55$ & \\
\hline & Housewife & $273(40.2)$ & $14.19 \pm 3.81$ & \\
\hline & Others & $148(21.8)$ & $11.85 \pm 2.93$ & \\
\hline \multirow[t]{5}{*}{ Level of Education } & illiterate & $330(48.6)$ & $12.96 \pm 3.27$ & \multirow[t]{5}{*}{$<0.001$} \\
\hline & Elementary & $293(43.2)$ & $13.71 \pm 3.76$ & \\
\hline & Secondary & $19(2.8)$ & $18.63 \pm 1.21$ & \\
\hline & High school & $19(2.8)$ & $18.84 \pm 1.46$ & \\
\hline & Academic & $18(2.7)$ & $19.16 \pm 1.50$ & \\
\hline \multirow[t]{4}{*}{ Source of Income } & Shopping and Savings & $35(5.2)$ & $14.51 \pm 4.59$ & \multirow[t]{4}{*}{0.001} \\
\hline & Buy without savings & $147(21.6)$ & $13.32 \pm 3.35$ & \\
\hline & Just buy the necessary supplies & $431(63.5)$ & $14.09 \pm 3.78$ & \\
\hline & Lack of purchasing power & $431(63.5)$ & $14.09 \pm 3.78$ & \\
\hline \multirow[t]{3}{*}{ Number of children } & Less and equal 3 & $175(25.8)$ & $13.96 \pm 3.78$ & \multirow[t]{3}{*}{0.059} \\
\hline & $6-4$ & $374(55.1)$ & $13.93 \pm 3.88$ & \\
\hline & More and equal 7 & $130(19.1)$ & $13.07 \pm 3.10$ & \\
\hline \multirow[t]{2}{*}{ Gender } & Male & $211(31.1)$ & $14.33 \pm 3.73$ & \multirow[t]{2}{*}{0.009} \\
\hline & Female & $468(68.9)$ & $13.52 \pm 3.71$ & \\
\hline \multirow[t]{3}{*}{ Marital Status } & Married & $352(51.8)$ & $14.27 \pm 3.87$ & \multirow[t]{3}{*}{0.013} \\
\hline & Widow/widower & $316(46.5)$ & $13.32 \pm 3.52$ & \\
\hline & divorced & $11(1.6)$ & $14.16 \pm 3.55$ & \\
\hline \multirow[t]{3}{*}{ Housing Situation } & Personal & $620(91.3)$ & $13.74 \pm 3.67$ & \multirow[t]{3}{*}{0.493} \\
\hline & Leased & $35(5.2)$ & $13.77 \pm 4.33$ & \\
\hline & Accommodation without payment & $24(3.5)$ & $14.66 \pm 4.28$ & \\
\hline
\end{tabular}


Table 2. Correlation between life satisfactions with the study variables

\begin{tabular}{|c|c|c|c|c|c|c|}
\hline \multicolumn{2}{|c|}{ Variable } & Age & Wellness status & Cognitive status & Social support & Daily activities \\
\hline Life satisfaction & $\mathrm{r}$ & -0.019 & 0.333 & 0.186 & 0.291 & 0.022 \\
\cline { 2 - 7 } & $\mathrm{p}$ & 0.614 & $<0.001$ & $<0.001$ & $<0.001$ & 0.564 \\
\hline
\end{tabular}

Table 3: Results of regression analysis of factors affecting life satisfaction

\begin{tabular}{|c|c|c|c|c|c|}
\hline predictive variable & B & S.E & B & t & P-Value \\
\hline Constant & 8.062 & 0.817 & - & 9.761 & 0.001 \\
\hline Wellness & 0.142 & 0.231 & 0.253 & 6.103 & 0.001 \\
\hline social support & 0.048 & 0.009 & 0.204 & 5.362 & 0.001 \\
\hline Cognitive status & 0.177 & 0.065 & 0.107 & 2.719 & 0.007 \\
\hline Everyday life activities & $0.109-$ & 0.045 & -0.091 & -2.392 & 0.017 \\
\hline \multicolumn{6}{|c|}{$\mathrm{R}=0.403, \mathrm{R}^{2}=0.163, \mathrm{~F}=23.21, \mathrm{P}<0.001$} \\
\hline
\end{tabular}

